\title{
DE CIUDADES QUE PRODUCEN A CIUDADES QUE CUIDAN. LOS TERRITORIOS COMO EJES PARA ABORDAR LA PANDEMIA Y LA CRISIS SOCIAL
}

Paola Jirón Martínez. 


\section{PAOLA JIRÓN MARTÍNEZ}

Doctora en Planificación Urbana y Regional de la Facultad de Arquitectura y Urbanismo de la London School of Economics and Political Science. Profesora Asociada de la Facultad de Arquitectura y Urbanismo de la Universidad de Chile. Directora del Núcleo Milenio Movyt e investigadora asociada del Centro de Estudios de Conflicto y Cohesión Social, Coes.

Cuenta con una amplia experiencia en investigación en temas de movilidad cotidiana, metodologías de investigación y la aplicación de teorías feministas a los estudios urbanos. 


\section{DE CIUDADES QUE PRODUCEN A CIUDADES QUE CUIDAN. LOS TERRITORIOS COMO EJES PARA ABORDAR LA PANDEMIA Y LA CRISIS SOCIAL}

\section{INTRODUCCIÓN}

La pandemia global ha evidenciado que los territorios en general y la movilidad en particular son fundamentales como posibilidades para enfrentar la crisis actual. En nuestro país hemos visto cómo las múltiples escalas, diversas relaciones y dimensiones territoriales han devenido en elementos sustanciales para el esparcimiento del virus. Sobre todo, la movilidad o la imposibilidad de dejar de moverse ha tenido efectos innegables, pues ha evidenciado las desigualdades que enfrenta la población, las que se hacen particularmente evidentes cuando los territorios están de por medio. Lo que observamos no solo se refiere a lo esencial de la movilidad con relación al uso del espacio público y el transporte - que muchos hemos tenido que abandonar, sino a comprender que, pese a que algunos se pueden mantener quietos en sus hogares y realizar teletrabajo, muchas otras personas y otras cosas se siguen moviendo, lo que permite a muchos mantenerse fijos. Adicionalmente, aquellos que no pueden quedarse quietos en sus casas no siempre lo hacen solo porque no les gusta seguir instrucciones, sino porque les es imposible quedarse en el hogar, ya sea porque no perciben los ingresos necesarios para vivir, porque viven con altos niveles de hacinamiento en sus lugares de residencia o por las distancias a servicios e infraestructuras necesarias para sobrellevar estos difíciles momentos. Esto da cuenta de la importancia de los territorios relacionales y móviles en el macro de la vida cotidiana hoy.

Sin embargo, los territorios no han sido considerados como estructurantes de la forma en que se conformarán los impactos del virus, al menos en Chile. Se han privilegiado las visiones parciales o en términos de salud o en términos económicos macro, dejando de lado las vidas de las personas en sus diversas formas de habitar los territorios. Algo que se hace evidente es que los habitantes de nuestras ciudades han tenido que salir a las calles desprovistos de cuidados por parte del Estado y asumir su autocuidado de manera individual en un inicio y comunitariamente a medida que pasaban las semanas. Lo que ha emergido de manera central como consecuencia de la forma en que vivimos la pandemia es la urgente importancia de los cuidados en nuestra sociedad. Por un lado, al estar encerrados se han entrecruzado estudios, trabajo y salud con las tareas domésticas, que incluyen los múltiples cuidados 
familiares. Estas labores de cuidado, que han estado presentes en el debate feminista desde hace muchos años, de pronto se hacen evidentes para todos los integrantes del hogar y evidencian la diversidad y cantidad de tareas que estas implican. Por otro lado, las medidas tomadas por las autoridades han sido insuficientes para cuidar adecuadamente a la ciudadanía, lo que ha generado malestar, aumento de enfermos, hambre y un creciente descuido, que han conducido a una resurgencia de apoyos vecinales y comunitarios para cuidar a la población descuidada.

Este documento intenta recoger estas urgencias de cuidado para plantear la necesidad de convertir parte de las experiencias vividas como ciudadanos en posibilidades para repensar nuestras ciudades en el futuro. Mucho se ha hablado sobre cómo las ciudades, por el alejamiento del espacio público, van a perder sentido tras la pandemia o cómo disminuirá el uso el transporte público en favor del transporte privado o la bicicleta. Sin embargo, aquí se plantea que más que buscar soluciones inmediatas respecto a cómo deben responder las ciudades, es necesario comenzar a repensar profundamente cómo las ciudades pueden ser un eje fundamental en la manera en que nos repensamos como sociedad y pasamos de ser una enfocada en la producción como centro de su ser a una que se cuida para su reproducción.

El documento se estructura en tres partes. Primero, se explica cómo se entienden los territorios relacionales y su relación con las movilidades, y el rol de los territorios y las movilidades en la situación de crisis actual. Luego, se plantea la necesidad de reconocer los conocimientos territoriales existentes y buscar formas de mediar o hacer dialogar los diversos conocimientos presentes en las decisiones que impactan a los habitantes de las ciudades, con el fin de realizar intervenciones que sean menos fragmentadoras de las vidas y más integrales tanto en términos urbanísticos como de políticas públicas en general. Finalmente, se explica cómo esta visión del territorio y los conocimientos territoriales nos lleva a reconocer la importancia de los cuidados como eje de la forma en que podemos pensar las ciudades a futuro, a fin de no solo asignar los cuidados de manera individual y privada — generalmente a las mujeres- sino de colectivizar los cuidados como sociedad.

\section{TERRITORIOS RELACIONALES Y MOVILIDAD}

La comprensión del territorio como relacional (Massey, 2005) implica verlo como más que un mero contenedor de actividades o un espacio que se analiza desde arriba o desde indicadores georreferenciados en un mapa, el cual se puede controlar desde la distancia y permitiría predecir cómo se va a comportar la población. Entender el territorio como relacional implica reconocer que este nos impacta, así como 
nosotros lo impactamos con nuestras prácticas y nuestros cuerpos, es entender que aquello que sucede en un lugar tiene consecuencias en otro, aunque sea lejano y a veces imperceptible. También implica entender que la experiencia territorial no es igual para todos y que diversas personas la viven de manera distinta según su nivel socioeconómico, pero también dependiendo de su género, edad, ciclo de vida, etnia, habilidades, etc. Es decir, los impactos en la forma en que se interviene el territorio son diferenciados y se deben observar en su interseccionalidad (Rodó \& Baylina; Hopkins, 2018). Y, sobre todo, es comprender que el territorio es dinámico, o sea, que los territorios no son fijos, ya que quienes los habitamos, humanos y no humanos, los vivimos en constante movimiento.

Para esto, la movilidad o, más precisamente, las movilidades, pueden ayudar a comprender la importancia del territorio en la crisis actual. La movilidad no se refiere solo a la manera en que las personas, sus cuerpos, las cosas - incluidos los virus- $y$ las enfermedades se mueven, sino al impacto que estas movilidades tienen en las vidas de quienes se mueven (Jirón \& Imilán, 2018). Es decir, a la manera en que las vidas de las personas están interrelacionadas y son interdependientes con la movilidad - virtual, imaginativa y comunicativa; de recursos, ideas, conocimiento, dinero, trámites, pedidos- todos los otros desplazamientos que nos permiten movernos en el mundo actual (Jirón \& Gómez, 2018; Jirón \& Carrasco, 2020). En concreto: todo se mueve y, al mismo tiempo, estas movilidades también se encuentran inexorablemente vinculadas a múltiples formas de inmovilidad.

Esto quiere decir que para que parte de los habitantes de las ciudades se puedan quedar en casa y trabajar desde allí, otros se siguen moviendo, incluidas aquellas personas que retiran la basura, realizan repartos a domicilio, manejan buses, trabajan como profesionales de la salud, venden alimentos o hacen fluir los millones de mensajes que continúan circulando por las redes sociales para mantener la cercanía social pese al distanciamiento físico. Y, adicionalmente, se mueven todas aquellas personas que tienen que salir todos los días a conseguir los recursos necesarios para vivir. Dicho de otro modo, aquellas personas que podemos permanecer fijas en estos momentos somos las privilegiaas, pues tenemos el lujo de poder mantenernos en casa.

\section{EL DESCONOCIMIENTO DE LOS TERRITORIOS EN MOVIMIENTO}

El aislamiento no es posible para todos. En Chile se implementaron durante varios meses cuarentenas dinámicas, lo que confinó a los habitantes de algunos sectores de la ciudad para evitar el esparcimiento del virus. Sin embargo, esta mirada fija del territorio no concuerda con la dinámica móvil del virus y de las personas que lo 
portan. En otras palabras, dentro de las principales fallas de las medidas tomadas en Chile estaba una doble ceguera: primero, pensar que dejando a algunos pocos inmóviles en sus casas se iba a controlar el virus a pesar de que el resto de la población se seguía moviendo; y segundo, desconocer que inmovilizar a toda la población implicaba advertir las diversas fragilidades territoriales preexistentes. Debido a que la movilidad es interdependiente (Jirón \& Carrasco, 2020), cada vez que solicitamos un delivery, que pasan a retirarnos la basura, que los conserjes de los edificios llegan a trabajar o que alguien cruza la zona de cuarentena, las probabilidades de que el virus circule aumentan.

Es precisamente el privilegio de inmovilidad el que nos ha develado la fragilidad, precariedad y desigualdad del sistema urbano en el que vivimos hoy. La salud, el comercio, el transporte y el empleo son demasiado frágiles. Hemos podido constatar que existe un alto nivel de empleo informal y precario, lo que ha hecho que, en muy poco tiempo, millones de personas hayan quedado sin remuneración, lo que las ha obligado a salir a pesar del riesgo de enfermarse y a recurrir al mismo tiempo a sistemas de salud que no dan abasto. Se observa precariedad en las formas de habitar, donde los más pobres tienen que seguir funcionando, arriesgando su salud y la de los demás; muchas mujeres tienen que dedicarse al cuidado de los niños y enfermos y, además, seguir trabajando; muchos adultos mayores que ya se encontraban solos tienen que aislarse aún más para no enfermar o morir; algunas mujeres deben permanecer encerradas con sus posibles victimarios. Millones han tenido que enfrentar lo que es vivir en un sistema que no nos cuida y recurrir a formas de cuidado individuales o crecientemente comunitarias para poder sobrevivir.

Esto da cuenta de tomadores de decisiones que desconocen los territorios, que disponen desde sus privilegios medidas que protegen a algunos y no a toda la población. La preocupación inicial fue que aquellos que vivían en algunas zonas de la ciudad no salieran, pero aquellos guardados también pueden contagiar a los que están fuera solo por la interdependencia de la movilidad.

Quizás lo más desconcertante de la situación actual es que los tomadores de decisiones desconocen a su población y que la gran mayoría de los habitantes de nuestras ciudades carece de condiciones suficientes para quedarse encerrados y viven en condiciones de alto nivel de vulnerabilidad y precariedad. Sin embargo, este privilegio de la inmovilidad duró muy poco, porque el territorio se mueve, porque todo se mueve. Esta crisis devela grandes desigualdades territoriales no solo por la falta de atención a los campamentos sin agua, la mala dotación de servicios de salud y otras infraestructuras en áreas más pobres de la ciudad, sino que, principalmente, por no contemplar que el territorio se mueve a medida que las personas se mueven y que, entonces, muchas personas están obligadas a moverse para subsistir. Esto significa no solo que muchos tienen que salir a trabajar en auto, bicicleta, caminando 
o en transporte público, sino que también tienen que hacer trámites, ir al médico, sacar licencias, permisos, cobrar cheques o seguir tratamientos.

\section{LOS SABERES Y CONOCIMIENTOS TERRITORIALES}

Por otra parte, se discute respecto a formas de controlar el territorio desde la inteligencia territorial, es decir, a partir de sistemas tecnológicos inteligentes. Podría ser muy útil contar con dicha información, sin embargo, por mucho que existan los softwares y capacidad técnica para manejar grandes bases de datos inteligentes que permitan hacer proyecciones, conocer cómo se mueven las personas, modelar el futuro y controlar a la población-, nuestros datos son precarios, incompletos y nuestras formas de enfrentar la crisis son insuficientes, particularmente cuando no existe claridad respecto a quiénes son los habitantes que se verán afectados por ella. Hemos visto que no sabemos cómo pararnos en una fila para comprar en el supermercado manteniendo la distancia; cómo los lugares donde es necesario hacer trámites no cuentan con los implementos de seguridad para sus empleados y menos para los clientes; y cómo los centros médicos, que debieran hacerlo, no cumplen los protocolos. No se trata de que los datos no sean fidedignos, sino que son incompletos. Existe mucha información difícil de obtener a partir de los grandes sistemas de datos, pero que resulta crucial al momento de tomar decisiones, más allá de controlar y saber dónde están las personas a cada momento.

Esto significa que los habitantes de la ciudad llevamos en nuestros cuerpos un tipo de inteligencia que nos permite enfrentar esta crisis de otras maneras o de formas complementarias. Pero el mundo político, empresarial y de los expertos no ha sabido aprovechar dichos saberes ni entender cómo la ciudadanía habita los territorios, algo que se volvió evidente en la crisis social que comenzó en Chile a partir del 18 de octubre de 2019. Tampoco estamos entendiendo las dificultades que enfrentan, en lo cotidiano, la mayoría de los habitantes. Débilmente comprendemos la diversidad de experiencias de este habitar, pues no todos habitamos de manera similar. Las decisiones de la vida cotidiana se toman teniendo a la vista muchas dimensiones con las que vivimos todos los días y aún no comprendemos cómo las materialidades, los objetos y el espacio generan o inhiben posibilidades para las personas.

La forma en que expertos, de distintas disciplinas, descomponen su especialidad, fragmentan el territorio para comprender la ciudad y la intervienen con sistemas e infraestructuras aisladas entre sí da cuenta de su exigua comprensión de cómo vivimos, que no responde a una forma parcial y sectorial de pensar e intervenir, la que en última instancia fragmenta aún más la vida de las personas y, por ende, la precariza. 
Que Chile se sorprendiera con una crisis que no veía venir devela la poca conexión que existe entre las disciplinas que mantienen fragmentado su análisis y su aplicación a las políticas públicas. La inteligencia territorial debiese ir más allá de contar con datos macro sobre cómo se comportan de manera agregada los individuos. Es fundamental considerar la inteligencia situada, proveniente de lo/as mismos habitantes, para enfrentar esta crisis. No es que el conocimiento de los expertos no sirva, sino que es incompleto y requiere complementarse, mediar, dialogar (de Sousa, 2009) con muchos otros conocimientos. Y eso es urgente hoy: reconocer el habitar y, en particular, el conocimiento territorial habitado.

Este conocimiento nos muestra fragilidad y precariedad en nuestro habitar y, a la vez, nos devela otras formas de saber vivir entre nosotros, las que demuestran altos niveles de colaboración, solidaridad y preocupación por el prójimo; ingenio y astucia para enfrentar la crisis; formas alternativas y creativas de movimiento que nos permitirán salir mejor de esto. De estos saberes podemos aprender tanto en tiempos de crisis como en el momento en que tengamos que retomar la vida, que definitivamente será distinta. Y la forma de pensar las ciudades debe empezar a comprender estos modos móviles en que se habitan los territorios, no solo algunos privilegiados, sino que todos. Las formas en que vivimos se invisibilizan, lo que produce un descuido generalizado que ya no se sostiene, por lo que aparece como fundamental retomar lo que indica la economía feminista: "son precisamente esas tareas relacionadas con la reproducción de la vida y los cuidados de las personas las que este sistema económico ha invisibilizado" (Jubeto et al., 2012).

\section{LOS CUIDADOS Y LA CIUDAD}

El trabajo proveniente de las teorías feministas respecto a la reproducción social resulta fundamental para situar la discusión sobre la importancia del territorio en la crisis actual, particularmente en cuanto a las relaciones de cuidado que se despliegan en él. Desde la teoría feminista, la esfera de la reproducción social se refiere a la forma en que la vida es mantenida y reproducida a nivel cotidiano y generacional, como plantean las economistas feministas. Por otro lado, las teorías feministas decoloniales y en particular las comunitarias, que se basan en el buen vivir, recogen una visión del mundo centrada en el ser humano como parte de un entorno natural y social. Ellas, junto a la mirada ecofeminista de la sustentabilidad de la vida, proponen una forma de comprender la reproducción de la existencia como algo que va mucho mas allá de la inserción de las mujeres al trabajo asalariado o la remuneración del trabajo doméstico, y apuntan a reconocer diversas formas de habitar que respeten la relación entre humanos, no humanos y el medioambiente 
(Vega Solís, 2019). La noción de cuidado se vuelve fundamental en esta forma de reconocer el habitar en el planeta.

Según la economía feminista, las tareas de cuidado han sido "realizadas históricamente por mujeres, que han visto cómo dichos trabajos se realizan de manera no remunerada o, en su caso, en condiciones precarias y, siempre, sin ser lo suficientemente reconocidas y valoradas socialmente" (Jubeto et al., 2012, p. 7). Estas feministas plantean una contradicción que el capitalismo tiene con el propio sostén de la vida y la sostenibilidad medioambiental del planeta. El ecofeminismo ha sido especialmente crítico con la forma en que se concibe la economía y propone

una transformación de las prácticas del ciclo económico relacionadas tradicionalmente con la producción, la distribución, la financiación y el consumo. Colocando en definitiva a las personas, al planeta y a su propia sostenibilidad en el centro de la construcción política, social y económica (Jubeto et al., 2012, p. 7).

Según Carrasco (2012), la reproducción de la vida es una noción multidimensional que incluye diversas sostenibilidades: ecológica, económica, social y humana, y todas las interrelaciones que existen entre ellas, lo que da lugar a la cadena del sostén de la vida. Esto es algo que el pensamiento económico dominante ha ocultado, al tiempo que ha invisibilizado que las condiciones de funcionamiento del sistema socioeconómico actual son insostenibles.

Una economía sostenible que trabaje para la satisfacción de las necesidades de todos los seres humanos, manteniendo la capacidad de reproducción de su mundo común social y natural, debe invertir la relación del "iceberg" y poner la producción y el mercado al servicio de las comunidades y las personas (Carrasco, 2012, p. 37).

Es por esto que, ante la lentitud o derechamente ausencia de respuesta del Estado frente a la magnitud de la crisis actual, las personas han tenido que, inicialmente de manera individual y luego colectiva, responder. Se ha observado en estos últimos meses $^{1}$ cómo los habitantes de la ciudad de Santiago han tenido que aceptar las nuevas condiciones o, de lo contrario, adaptarse, improvisar o transformarse:

1. El Núcleo Milenio Movyt ha hecho un seguimiento etnográfico a personas que se han mantenido en movimiento desde el inicio de las cuarentenas en Santiago (marzo, abril, mayo y junio, 2020). 
adaptar las formas de habitar, cambiar rutinas, aprender a usar nuevas tecnologías; improvisar con la forma de trabajar, vendiendo lo que se tiene, aprovechando los recursos con los que se cuenta: teléfonos, automóviles, permisos para enfrentar la crisis, entre otros; transformar los modos de trabajo, pues muchos incluso han tenido que cambiar de rubro. Todo esto se enfrenta con incertidumbre, ansiedad, preocupación y, sobre todo, miedo.

En síntesis, a la luz de una crisis social, económica y sanitaria que se palpa de manera crítica a nivel territorial, y frente a un Estado que no cuida, los habitantes han tenido que autocuidarse. Inicialmente, de las respuestas individuales comenzaron a surgir emprendimientos y soluciones a través de lo que se podía comprar, pero pronto eso no fue suficiente para todos. Así surgió el apoyo colectivo frente a la pandemia. Desde vecinos que se cuidan entre ellos, que ayudan a los más frágiles comprando o haciendo trámites para los adultos mayores o enfermos de los edificios, hasta formas colaborativas de apoyo que usan las redes sociales para organizar ollas comunes y centros de acopio por todo el país.

En concreto, lo que hemos visto son las formas en que, desde sus conocimientos territoriales, los habitantes y sus redes comienzan a cuidarse frente a un Estado que no lo hace, que no los conoce y que no sabe cómo enfrentar los momentos difíciles. En este contexto, ¿qué se puede comenzar a aprender de esta crisis? Que los saberes colectivos y territoriales comienzan a suplir y cuidar efectivamente a sus habitantes. Esto nos lleva a pensar cómo pasamos de una ciudad que está enfocada a ser más eficiente en sus sistemas de transporte, sus sistemas urbanos y las infraestructuras, hacia a una ciudad que mira a sus habitantes y procura que se reproduzca la vida, cuidando no solo a los humanos, sino también a las relaciones con no humanos como el medioambiente, las mascotas, entre otros. Pensar en los cuidados comienza a ser fundamental.

¿Cuáles serían los elementos principales que caracterizan a las ciudades que cuidan? Aquí se plantea que se trata de prácticas de cuidado, lugares de cuidado, materialidades del cuidado y sujetos de cuidado. Las prácticas de cuidado se refieren a aquellas actividades que se requieren para reproducir la vida, como criar, comunicarse, mantener la salud, alimentar, asear y mantener la ciudad, proveer de estabilidad emocional y afectiva, entre muchas otras. Los lugares de cuidado son los espacios donde suceden las labores de cuidado, que incluirían lugares de cuidado de niños, como guarderías, el hogar, hospitales y centros de salud; lugares de alimentación, parques, bibliotecas y museos, entre otros. Estos serían espacios para cuidar y ser cuidados. Algunos de estos son permanentes y otros son transitorios, como espacios de albergue temporal. Esta distinción no solo aborda los espacios íntimos de la vivienda, sino sobre todo los públicos. Estos son creados por medio del trabajo de cuidado e intenciones de los usuarios, lo que incluye a los funcionarios, 
residentes y visitantes que se relacionan con el entorno material donde se localizan. Las materialidades del cuidado se refieren a cómo los objetos, cuerpos, edificios o materiales se vinculan y dan forma a la naturaleza y posibilidad de cuidados. Estos incluyen los pavimentos, coches de bebé, automóviles, viviendas, edificios. Por otro lado, existe una discusión sobre quiénes son sujetos de cuidado, ya que estos no solo son receptores de cuidado, sino que también son activos dadores de cuidado, es decir, estas relaciones son siempre interdependientes. Estos posibles sujetos pueden incluir a las personas sin casa, migrantes indocumentados, allegados, niños, adultos mayores, jóvenes, el medio ambiente y las cooperativas alimenticias, entre muchos otros (Power \& Williams, 2020).

$\mathrm{Al}$ respecto, las inequidades interseccionales (Rodó-de-Zárate \& Baylina, 2018) que dan forma a las responsabilidades de cuidado dan cuenta de que en general son mujeres de grupos marginales, migrantes, muchas veces con poco reconocimiento social y económico, quienes se llevan gran parte del peso de los cuidados. Se ha detectado cómo estos grupos de cuidadores no son contemplados por la planificación urbana y de transporte. Las actividades de cuidado son todas aquellas que permiten la reproducción de la vida, como ir a dejar a los niños al colegio, comprar alimentos, llevar a alguien al médico, cocinar, hacer ejercicios, entre muchos otros. La crisis sanitaria que estamos viviendo ha evidenciado la importancia de los cuidados en el ámbito doméstico, situación que hace mucho tiempo las feministas han intentado evidenciar ${ }^{2}$. Pero la realidad colaborativa en el país ha mostrado que también existen los cuidados sociales (Daly \& Lewis, 2000) y que cuando estos se hacen colectivos y comunitarios comienzan a dar cuenta de formas en que las comunidades se cuidan entre sí.

\section{CONCLUSIONES}

Esta discusión nos lleva a pensar cómo remiramos la ciudad en torno a los múltiples cuidados que se ejercen allí y las diversas disciplinas que debieran intervenir para mejorar las prácticas de los cuidados, los espacios, las materialidades y los elementos del urbanismo. Pero la pandemia también nos devela que tanto las medidas inmediatas como las políticas públicas en general no consideran el territorio como eje fundamental en su implementación, por lo que se habla de "políticas territorialmente ciegas".

2. Ver Hayden, 1980, 1981, 1986; Madigan, Munro \& Smith, 1990; Watson, 1988. 
Esta desconexión territorial emerge de un análisis de los problemas sociales que se realiza de manera fragmentada o que mira al país como un todo homogéneo, ignorando los impactos territoriales heterogéneos en los que intervienen las políticas. Es particularmente crítica la carencia de miradas interdisciplinares y respuestas sectoriales, lo que termina fragmentando la experiencia territorial y genera intervenciones que desconocen las complejidades territoriales, aplastando cualquier posibilidad de acercamiento efectivo o mejoramiento de las formas en que se reproduce la vida.

Desde la mirada territorial, parece de especial importancia contar con políticas relacionadas con la movilidad, pero también con la vivienda, infraestructuras, localización de servicios, tiempos, ritmos y horarios de funcionamiento de la ciudad, políticas de salud, educación, previsión, trabajo y otros aspectos sociales, entre muchas otros factores, las que debieran estar enfocadas a cuidar social y territorialmente a la ciudadanía en vez de fragmentar sus vidas y hacer que los habitantes se cuiden de manera individual y privada. Esto implica reconocer, en primer lugar, la importancia de los cuidados, detectar las prácticas, espacios, materialidades y sujetos de cuidado, y luego, colectivizarlos, es decir, hacer que estas responsabilidades recaigan en toda la sociedad y no solo en algunas personas que se llevan la sobrecarga de estos, que son fundamentales para la producción capitalista; si la reproducción de la vida no se pone por sobre la producción, tampoco esta será posible. 


\section{REFERENCIAS}

Carrasco, C. (2012). "Economía, trabajos y sustentabilidad de la vida". En: Jubeto, Y. et al. (2012). Sostenibilidad de la vida. Aportaciones desde la economía solidaria, feminista y ecológica. Red de Economía Solidaria y Alternativa: Bilbao.

Daly, M. \& J. Lewis (2000). The concept of social care and the analysis of contemporary welfare states. The British Journal of Sociology 51(2) pp. 281298 https://doi.org/10.1111/j.1468-4446.2000.00281.x.

De Sousa Santos, B. (2009). Una epistemología del sur: la reinvención del conocimiento y la emancipación social. México: Siglo XXI-Clacso.

Jirón, P. \& J.A. Carrasco (2020). "Understanding daily mobility strategies through ethnographic, time use, and social network lenses". Sustainability 12(1), 312; https://doi.org/10.3390/su12010312.

Jirón, P. \& W. Imilán (2018). "Moviendo los estudios urbanos. La movilidad como objeto de estudio o como enfoque para comprender la ciudad contemporánea", Quid16, Revista del Área de Estudios Urbanos (10), 17-36.

Jirón, P. \& J. Gómez (2018). "Interdependencia, cuidado y género desde las estrategias de movilidad en la ciudad de Santiago". Tempo Social, Revista de Sociología da USP vol. 30, no.2, São Paulo, mayo/ago. 2018.

Jubeto, Y., M. Larrañaga, C. Carrasco, M. León, Y. Herrero, C. Salazar, C. de la Cruz, L. Salcedo, E. Pérez (2012). Sostenibilidad de la vida. Aportaciones desde la economía solidaria, feminista y ecológica. Red de Economía Solidaria y Alternativa: Bilbao.

Massey, D. (2005). For space. Sage, London. 222 p.

Hopkins, P. (2018). Feminist geographies and intersectionality, gender, place \& culture, DOI: 10.1080/0966369X.2018.1460331.

Power, E. \& M.J. Williams (2020). Cities of care: a platform for urban geographical care research. Geography Compass 20, e12474 DOI: 10.1111/gec3.12474.

Rodó-de-Zárate, M. \& M. Baylina (2018). Intersectionality in feminist geographies, gender, place \& culture, DOI: 10.1080/0966369X.2018.1453489.

Vega Solís, C. (2019). "Reproducción social y cuidados en la reinvención de lo común. Aportes conceptuales y analíticos desde los feminismos", Revista de Estudios Sociales 70. Publicado el 09 octubre, consultado el 12 octubre de 2019. URL: http:// journals.openedition.org/revestudsoc/46482. 